\title{
Redução da instabilidade e melhoria de desempenho do sistema MRP
}

\author{
Moacir Godinho Filho \\ Flavio Cesar Faria Fernandes \\ Universidade Federal de São Carlos
}

\begin{abstract}
Resumo
O artigo propõe um método para melhorar o desempenho do sistema MRP em um estudo de caso, uma grande empresa que produz materiais para escrita. O método é conseqüência de um levantamento bibliográfico e de características particulares do estudo de caso. Este método parte do princípio de que a melhoria de desempenho dos sistemas MRP é viabilizada pela redução no grau de instabilidade de tais sistemas e esta por sua vez só pode ser conseguida por meio de dois fatores-chave: i) uma correta parametrização do sistema e ii) um planejamento e programação da produção integrados voltados para a elaboração de um Plano Mestre de Produção (MPS) factível, respeitando as limitações de cálculo de capacidade do sistema. 0 método foi implementado e os resultados foram: uma redução drástica na instabilidade do sistema, com conseqüente redução nos custos dos estoques, melhoria no nível de serviço e aumento da satisfação e confiança das pessoas com relação ao sistema.
\end{abstract}

\section{Palavras-chave}

Sistema MRP, redução da instabilidade, melhoria de desempenho, estudo de caso.

\section{MRP system: nervousness reduction and performance improvement}

\begin{abstract}
The paper presents a method designed to get an improvement of the system performance in a case study, a large company that produces materials for writing. The method arises from a literature survey and from the particular characteristics of the case study. The method argues that the improvement on MRP performance is attained by system nervousness reduction which is supported by two main factors: i] system parameters must be determined in a precise way; iil integrated production planning and scheduling focused on development of a realistic Master Production Schedule (MPSJ, which takes account the system capacity. The method was applied and the results were: reduction of system nervousness, reduction of inventory costs, improvement of service level, increase of the workers satisfaction and increase the reliance on the MRP system.
\end{abstract}

\section{Key words}

MRP system, system nervousness reduction, performance improvement, case study. 


\section{INTRODUĈ̣̃O}

Os SPCP (sistemas de planejamento e controle da produção) são sistemas que provêem informações que suportam o gerenciamento eficaz do fluxo de materiais, da utilização de mão-de-obra e equipamentos, a coordenação das atividades internas com as atividades dos fornecedores e distribuidores e a comunicação/interface com os clientes no que se refere a suas necessidades operacionais (CORRÊA \& GIANESI, 1996).Um dos mais importantes e utilizados SPCP é o sistema MRP (Material Requirements Planning) e seu sucessor, o MRP II (Manufacturing Resources Planning).

Os maiores benefícios do sistema MRP são: diminuição dos custos de estoques, diminuição do leadtime dos produtos e aumento do nível de serviço ao cliente. Para Corrêa \& Gianesi (1996) o MRP é ideal para a empresa que tem como objetivos estratégicos prioritários o cumprimento de prazos e a redução de estoques. Porém, conseguir estes objetivos, na prática, nem sempre é tão fácil. Inúmeros problemas devem ser enfrentados pelos usuários dos sistemas MRP para que o desempenho desses sistemas possa ser satisfatório. Dentre os problemas podem ser citados: falhas na parametrização do sistema, a abordagem de capacidade infinita com a qual tais sistemas trabalham e a instabilidade desses sistemas. Esta instabilidade é chamada na literatura de "nervosismo do sistema" (system nervousness). Este termo é definido por Ho \& Ho (1999) como a modificação de datas e quantidades de ordens planejadas causando uma mudança no planejamento das prioridades destas ordens; quanto maior a ocorrência de reprogramações maior a instabilidade do sistema MRP.

Dentro deste contexto, o presente trabalho apresenta um método para se conseguir uma melhoria no desempenho do sistema MRP utilizado pela empresa do estudo de caso, uma grande empresa que produz materiais para escrita. O método proposto defende que uma correta parametrização do sistema, aliada a uma abordagem para tratar o problema da capacidade infinita do MRP no curto prazo levam a uma redução da instabilidade do MRP. Acreditamos que isto seja um pré-requisito para que se consigam melhorias no desempenho do sistema, ou seja: redução dos estoques e cumprimento de prazos. Este método foi implantado e os resultados foram promissores com relação à estabilidade do sistema, bem como reduções de estoque e melhoria no cumprimento dos prazos de entrega.

Vale ressaltar que o método pode facilmente ser adaptado e aplicado em empresas industriais de outros segmentos que utilizem o MRP. As adaptações necessárias dizem respeito à parametrização do MRP, que, embora deva seguir algumas diretrizes apontadas neste artigo para se conseguir a estabilidade do sistema, também depende de características dos produtos e dos processos de fabricação e compras da empresa.

A estrutura do trabalho é a que segue: na seção 2 é mostrada a estrutura metodológica seguida neste trabalho; na seção 3 apresenta-se o MRP, com seus benefícios e problemas; na seção 4 é analisada a situação inicial do caso estudado; na seção 5 é apresentado o método proposto; na seção 6 mostra-se a implantação; na seção 7 aparecem os resultados e na seção 8 são tecidas algumas conclusões.

\section{A ESTRUTURA METODOLÓGICA UTILIZADA NO TRABALHO}

O procedimento básico de pesquisa utilizado é o estudo de caso (já que são levantadas características particulares relacionadas ao uso de um sistema MRP em uma grande empresa produtora de materiais para escrita, bem como um problema é definido e solucionado pelo método proposto neste artigo). Para Yin (1994), "estudo de caso é uma forma de pesquisa empírica que visa investigar fenômenos contemporâneos, considerando o contexto real do fenômeno estudado". O estudo de caso se caracteriza como um tipo de pesquisa cujo objeto é uma unidade que se analisa profundamente (GODOY, 1995).

A Figura 1 ilustra o procedimento metodológico deste trabalho. A partir da revisão da literatura pertinente e das características particulares do estudo de caso, no qual foram levantados os principais problemas e deficiências do sistema MRP, propôs-se um método para a redução da instabilidade e melhoria do desempenho em sistemas MRP. Este método foi implantado na empresa pesquisada e os resultados obtidos foram bastante positivos. Apesar do estudo de caso não ter como objetivo a generalização estatística (BRYMAN, 1989), entende-se que os princípios gerais do método podem ser utilizados com êxito na solução de problemas similares em outras empresas que se utilizam do MRP.

\section{O MRP, SEUS BENEFÍCIOS E DEFICIÊNCIAS}

O MRP e o MRP II são os SPCP de grande porte que mais têm sido implementados em empresas de grande porte ao redor do mundo, desde os anos 70 (CORRÊ \& GIANESI, 1996). O MRP permite que, com base na decisão de produção dos produtos finais, seja determinado quais itens (semi-acabados, componentes e matériasprimas) produzir e comprar, bem como quando e quanto produzir e comprar. 
O MRP II é uma evolução do MRP, que leva em conta também decisões de capacidade, ou seja, inclui a questão de como produzir às questões já respondidas pelo MRP. O MRP II utiliza uma lógica estruturada de planejamento que prevê uma seqüência hierárquica de cálculos, verificações e decisões, visando chegar a um plano de produção viável em termos de disponibilidade de materiais e de capacidade produtiva. Neste trabalho denominamos os sistemas MRP e MRP II simplesmente como sistemas MRP.

Uma das grandes vantagens do MRP é que este sistema reage bem a mudanças, sendo portanto um sistema bastante útil no atual ambiente competitivo global, cada vez mais turbulento (CORRÊA \& GIANESI, 1996). Outra vantagem do MRP é tratar situações mais complexas, que envolvem um grande número de produtos, bem como estruturas de produtos com vários níveis e vários componentes por nível. Para MacCarthy \& Fernandes (2000) o MRP é um SPCP adequado para sistemas de produção não repetitivos. Como vimos anteriormente, os objetivos relacionados ao sistema MRP são a redução dos níveis de estoque e o cumprimento dos prazos.

Apesar de fornecer vantagens em determinadas situações e ser amplamente utilizado em empresas, várias questões importantes do MRP são negligenciadas pelas organizações. Tratamos neste trabalho de três destas questões:

i) a parametrização do sistema $\mathrm{MRP}=>$ de acordo com Corrêa et al. (2001) "a parametrização de sistemas MRP é, ao mesmo tempo, uma das atividades mais importantes e mais negligenciadas pelas organizações que o adotam";

ii) a capacidade infinita do sistema $\mathrm{MRP}=>$ apesar do MRPII ter módulos de cálculo de capacidade estes não são restritivos, ou seja, o sistema por si só não restringe a capacidade, gerando planos e a conseqüente explosão de quantidades infinitas para a produção. Para diversos autores (por exemplo, TAAL \& WORTMANN, 1997 e TEMPELMEIER, 1997) a incapacidade do sistema MRP em tratar problemas de capacidade e, portanto, gerar programas de produção factíveis (TEMPELMEIER, 1997; STEVENS, 1977) é um dos grandes problemas do sistema MRP;

iii) a instabilidade (necessidade de freqüentes reprogramações) que o sistema MRP pode apresentar. A instabilidade do sistema é um grande problema do MRP e precisa ser resolvido.

Estes três assuntos, apesar de serem tratados já algum tempo na literatura de Gestão da Produção (por exemplo, STEELE, 1975; MATHER, 1977; CARLSON et al, 1979); ainda são bastante atuais como mostram os recen-

Figura 1: Estrutura metodológica utilizado no trabalho

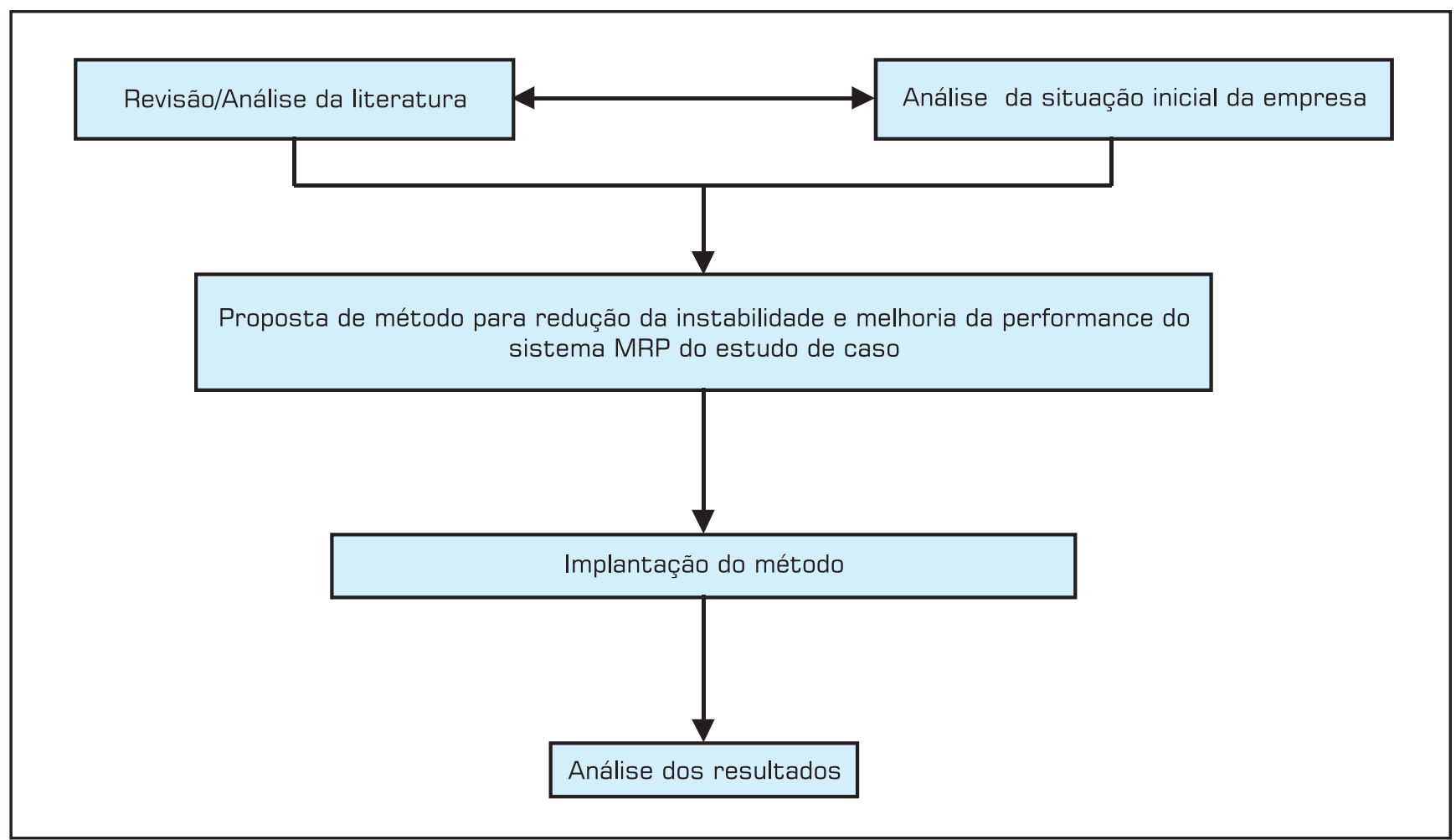


tes trabalhos de Xie et al., 2003; Yeung et al., 2003; Ho, 2002 , dentre outros. Isto mostra que apesar de existir um grande número de pesquisas na área este ainda não é um assunto esgotado. A razão para isto talvez esteja na falta de trabalhos práticos que visualizem situações reais das empresas. O presente trabalho vem exatamente contribuir nesta direção.

Os sistemas MRP II evoluíram com a finalidade de suportar as necessidades de informação de toda uma organização. Para se conseguir tal objetivo, mais módulos, que suportam mais funções, foram acrescentados e integrados aos sistemas MRP II, possibilitando um escopo muito maior do que somente a ênfase na manufatura. A partir deste ponto passam então a se denominar sistemas ERP (Enterprise Resource Planning ou Planejamento dos Recursos do Empreendimento).

\section{O ESTUDO DE CASO: ANÁLISE DA SITUAĈ̣̃O INICIAL DA EMPRESA}

\section{A empresa, sua estrutura e o processo pesquisado}

A empresa pesquisada se dedica à fabricação de material escolar, como lápis, borrachas, apontadores, lápis-de-cor, equipamentos para desenho técnico e artístico, tendo o lápis como o seu principal produto (é a segunda maior empresa mundial na produção de lápis). A empresa possui hoje, no Brasil, aproximadamente 3200 funcionários. Quanto à participação de mercado, a empresa lidera o setor de materiais escolares no Brasil com aproximadamente $60 \%$ do mercado.

Basicamente, a empresa se estrutura de acordo com os produtos acabados e semi-acabados que produz. Portanto, existem basicamente quatro departamentos de produção na empresa: i) produção de lápis; ii) produção de canetas (engloba borrachas e apontadores); iii) produção de embalagens; e iv) produção de produtos para supermercados. O departamento estudado neste trabalho é o departamento de produção de produtos para supermercados. Este departamento produz aproximadamente 80 produtos diferentes em seis tipos de processos. Três destes processos são formados por uma única máquina de conformação a quente, a qual efetua a montagem dos produtos. Os outros três processos são formados por um conjunto de três máquinas, as quais também realizam a montagem dos produtos. Uma observação importante é que cada um dos 80 tipos diferentes de produtos são produzidos necessariamente em apenas um dos seis tipos de processos.

A estrutura dos produtos deste departamento é uma estrutura de em média quatro níveis. O nível zero é o próprio produto final. O primeiro nível é composto por um plástico (material comprado), que é o material que será conformado a quente para a fabricação do produto, por um ou mais produtos que formam o conteúdo do produto (necessariamente um produto do departamento de lápis ou do departamento de canetas) e, finalmente, por um cartão que vem do departamento de embalagens. O nível 2 representa os materiais produzidos de cada um destes componentes. O nível 3 representa, de um modo geral, as matérias-primas utilizadas. O programador da produção do setor de supermercados mantém relacionamento com os outros três departamentos de produção da empresa, bem como com o setor de suprimentos, que cuida das compras.

\section{A situação inicial do MRP na empresa}

A empresa implementou recentemente o ERP SAP R3, que possui o módulo de MRP-II. Nesta seção mostramos como a empresa realizava o planejamento e controle da produção dentro do MRP e também como se configuravam os principais parâmetros deste sistema antes da implantação do método proposto, enfatizando os principais problemas referentes a estes dois tópicos. maior estabilidade do sistema MRP possibilita a redução de estoques e o aumento das porcentagens de entregas no prazo.
O planejamento e controle da produção (PCP) na empresa é composto basicamente por um setor de planejamento central $(\mathrm{PJ})$, por programadores das quatro áreas definidas anteriormente e por um programador de compras de matérias-primas. $\mathrm{O}$ processo de planejamento segue basicamente o processo hierárquico requerido pelo sistema MRP e é resumido a seguir. Partindo-se de uma previsão de vendas, o PJ realiza um planejamento agregado utilizando o módulo S\&OP do MRP. Este planejamento no longo prazo determina quantidades a serem produzidas mensalmente por família de produtos, verificando se há disponibilidade de capacidade para estes volumes agregados. Uma vez definidas estas quantidades, elas são desagregadas em produtos individuais, com base nas previsões individuais de cada produto, obtendose o plano-mestre de produção (MPS) da empresa. São realizadas algumas análises grosseiras de capacidade nos centros de trabalho considerados gargalos e então este MPS é explodido, gerando quantidades e datas de produção para todos os produtos da empresa, bem como quan- 
tidades e datas de compra das matérias-primas e de outros produtos comprados.

A produção da empresa pode ser caracterizada como estando em um grau intermediário entre a produção para estoque (uma vez que as vendas apresentam grande sazonalidade) e para grandes e importantes clientes. Um grande complicador ao PCP na empresa é a grande quantidade de novos produtos que a empresa cria ao longo do ano; por sinal, o departamento de marketing é tido como o mais vital para a empresa.

Dentro deste processo de planejamento e controle da produção na empresa foram identificados os seguintes problemas:

Problema 1: Existência de uma grande instabilidade no sistema MRP devido às freqüentes alterações no MPS e "rodadas" do MRP feitas pelo PJ, muitas vezes diariamente, devido a pressões da área de marketing da empresa. Qualquer tipo de programação dentro deste ambiente é totalmente inviável. número de parâmetros afeta o desempenho dos sistemas MRP (ver YEUNG et al. (1998)). A configuração desses parâmetros na empresa antes da implementação do método a ser proposto era a seguinte:

i) Período de "congelamento" (time fence) do MPS: O período de congelamento ou time fence é definido por Correa et al. (2001) como o período, com duração predefinida por parametrização, a partir do tempo presente, dentro do qual o controle sobre todas as ordens é tirado do sistema computacional e assumido pelo programador. Em outras palavras, neste período as ordens não são alteradas pelo sistema, pois entende-se que as alterações não são viáveis ou então os custos da mudança são maiores que os custos de não mudar; portanto, a adoção de um período de congelamento é vital para se conseguir estabilidade no sistema MRP. Na empresa inexistia um intervalo de tempo para o qual o MPS é mantido congelado.

ii) Freqüência de replanejamento do MPS: a frequiência adotada inicialmente na empresa era de uma semana, porém esta freqüência vinha diminuindo a ponto de chegar a ser diária em alguns casos. Muitas mensagens de reprogramação eram levadas em consideração, causando reprogramações muitas vezes diárias.

iii) Horizonte de planejamento do MPS: O horizonte de planejamento é o intervalo de tempo para o qual a programação da produção é efetuada. Na empre-

Problema 2: A abordagem infinita de capacidade é um grande problema para a empresa, uma vez que o cálculo de capacidades em nível de MPS não está sendo suficiente para avaliar a real capacidade dos centros de produção nem dos produtos acabados e tampouco dos itens semi-acabados. O resultado disto é a geração de quantidades a serem produzidas não condizentes com a capacidade dos setores produtivos, gerando, em alguns casos, falta de produtos, e, em outros, grande quantidade de estoques desnecessários.

Problema 3: Não há nenhuma integração, via MRP, entre os setores de produção da empresa. Dessa forma, as programações a curto prazo (diárias) são feitas somente dentro de cada setor, sem que haja uma integração dessa programação. Com isto, muitas vezes programa-se produzir um produto sem que se tenha o componente necessário; outras vezes o componente necessário permanece dias, até mesmo semanas, em estoque sem ser utilizado. A solução paliativa encontrada é uma tentativa de integração informal via telefone, que quase na maioria das vezes não é bem-sucedida, pois existem muitos setores de produção e a combinação de contatos entre estes é muito grande.

Com relação à parametrização do MRP, um grande sa este horizonte era de três meses.

iv) Previsão de demanda: a previsão de demanda baseava-se em média simples, era refeita com muita freqüência e não havia a posterior avaliação dos erros da previsão.

v) Estoque de segurança: apenas os produtos comprados tinham estoques de segurança; o cálculo destes estoques de segurança baseava-se somente em regras determinísticas, como, por exemplo, a adoção de uma margem de $20 \%$ a mais em cada pedido.

vi) Regras de tamanho de lote: em departamentos onde o custo da preparação de máquinas é alto (departamento de embalagens) eram utilizados grandes lotes de produção (30, 60, 90 dias ou até mais), tentando-se chegar a um lote econômico, gerando grande quantidade de estoque. Em outros departamentos eram utilizadas regras de tamanho de lote com necessidades fixas de um determinado período, como, por exemplo, a semana ou o mês.

vii) Leadtimes: O leadtime é o tempo entre a liberação de uma ordem e o momento a partir do qual o material está pronto e disponível para o uso. O MRP na empresa não apresenta o inconveniente de ter os leadtimes fixos, porém, por outro lado, os tempos no sistema estão cadastra- 
dos de maneira superdimensionada, gerando leadtimes extremamente longos e totalmente fora da realidade. Como conseqüência, produtos são planejados com grande antecedência, gerando estoques desnecessários.

viii) Sistema de controle de estoques: todas as matérias-primas são controladas pelo sistema de revisão contínua, independentemente de seu valor e do leadtime de fornecimento.

Os problemas apresentados com relação ao planejamento e programação da produção, bem como à parametrização, chegaram a se tornar uma ameaça ao sucesso da implantação do SAP R3 na empresa, uma vez que este sistema tem no MRP seu principal módulo.

\section{O MÉTODO PROPOSTO PARA SOLUC̣ÃO DO PROBLEMA DO ESTUDO DE CASO}

Nesta seção propomos um método para se conseguir uma redução da instabilidade e melhoria no desempenho dos sistemas MRP. O método supõe que as três questões negligenciadas do MRP discutidas anteriormente estão bastante relacionadas, uma vez que a melhoria na parametrização do sistema e a utilização de uma lógica de planejamento e programação da produção integrados que trate do problema da capacidade levam com certeza à redução da instabilidade no sistema. Esta afirmação é suportada por diversos autores, como, por exemplo, Koh et al, 2002; Kadipasaoglu \& Sridharan, 1997; Ho et al.,
1995. Esta maior estabilidade do sistema possibilita a redução de estoques e o aumento da porcentagem de entregas no prazo, além de trazer outros benefícios no longo prazo, como redução de custos de materiais refugados por obsolescência, aumento do grau de confiança e satisfação das pessoas no sistema, dentre outros benefícios. Além disso, esta estabilidade só pode ser conseguida com base na correta parametrização e no planejamento e programação integrados, conforme ilustrado na Figura 2.

\section{A parametrização do MRP para se conseguir estabilidade no sistema}

Com relação à correta parametrização, baseado em uma revisão bibliográfica, apresenta-se a seguir como devem se configurar os principais parâmetros do MRP para que se consiga a estabilidade no sistema.

\section{i) Período de "congelamento" do MPS}

Yeung et al. (1998) identificam na literatura dois métodos de utilização do time fence: o método baseado em ordens, no qual um certo número de ordens dentro do horizonte de planejamento são "congeladas", e o método baseado em períodos, no qual ordens dentro do time fence são "congeladas". Ainda de acordo com estes autores, evidências empíricas, como as mostradas em Sridharan et al. (1987) e Sridharan \& Berry (1990) demonstraram que o método baseado em ordens se comporta melhor que

Figura 2: Método para a redução da instabilidade e melhoria do desempenho em sistemas MRP

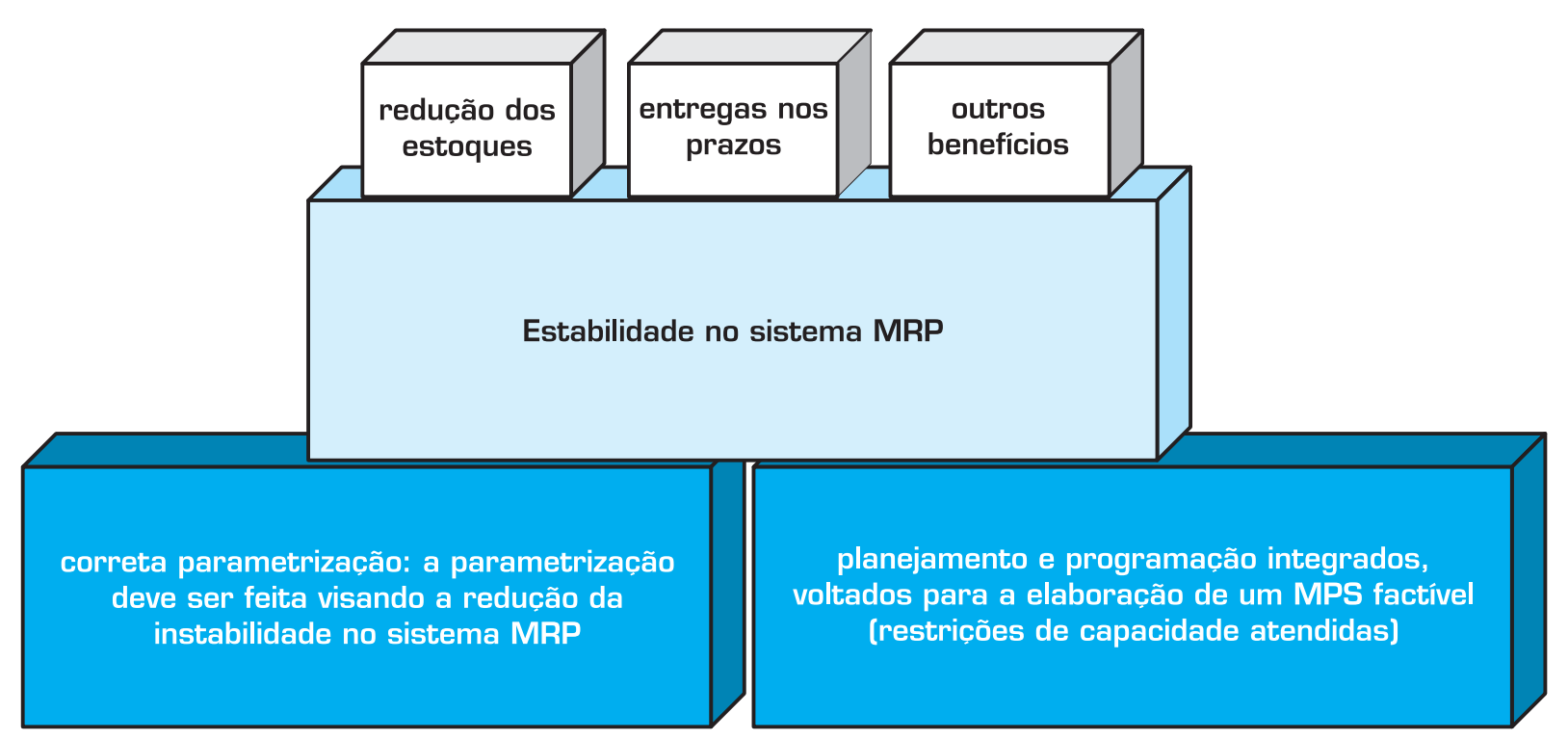


o método baseado em períodos. Apesar disso, o método baseado em ordens não é muito utilizado pelos usuários de MRP, pois, em uma situação prática com múltiplos itens e demanda incerta, este método pode gerar diferentes períodos de congelamento para cada item final após cada ciclo de replanejamento, gerando grande confusão no sistema (YEUNG et al., 1999).

A determinação do tamanho do período de "congelamento" é uma questão bastante importante dentro deste contexto. Para Correa et al. (2001) um bom valor é o leadtime acumulado do item, ou seja, o tempo total máximo para se produzir o item, bem como seus componentes, desprezando-se estoques existentes de materiais. Para Xie et al. (2003), quanto maior o período de congelamento menor a instabilidade no sistema. Com relação a esta determinação, Yeung et al. (1999) destacam a existência de dois tipos de períodos de congelamento: simples e múltiplo. No período de congelamento simples, o período de congelamento (denominaremos período de congelamento A) deve ser no mínimo igual ao leadtime acumulado do item somado ao intervalo de replanejamento. Já no período de congelamento múltiplo, o período de congelamento (denominaremos período de congelamento B) deve ser no mínimo igual ao intervalo de replanejamento somado ao leadtime do item. Observe que o leadtime do item, diferentemente do leadtime acumulado, não leva em conta os tempos de produção dos componentes dos itens, somente o tempo de produção do próprio item. Além disso, estes autores propõem um novo período denominado "período de semicongelamento" que corresponde à diferença entre os períodos de congelamento A e B mostrados. Este novo período corresponde a um intervalo no qual a programação pode ser alterada, porém é sujeita à verificação da disponibilidade de materiais. Yeung et al. (2003) concluem que a utilização do time fence múltiplo consegue melhores resultados em termos de custos e flexibilidade do que a utilização do time fence simples.

\section{ii) Frequiência de replanejamento do MPS}

Basicamente, a maioria dos trabalhos que trata da freqüência de replanejamento do MPS indica que replanejamentos muito freqüentes levam a um aumento no custo total, pois causam uma instabilidade muito grande no sistema. Este fato é comprovado em Xie et al., 2003. Ainda de acordo com estes autores, a periodicidade de replanejamento do MPS deve ser maior ou igual ao período de congelamento para se conseguir melhorias de custo, menor instabilidade e maior nível de serviço.

Um aspecto bastante importante a respeito do replanejamento no MPS é a questão das mensagens de reprogramação. Mensagens freqüentes criam uma grande instabilidade no sistema MRP. Existem várias abordagens na literatura para tratar tais mensagens, porém de acordo com Ho (1989) a mais adequada para reduzir as instabilidades no sistema é a chamada procedimento de suavização estática, criada por Mather (1977). Neste procedimento não se efetua a reprogramação das ordens de produção dentro de um prazo predeterminado. Também para Euwe et al. (1998) as mensagens de reprogramação são pouco utilizadas atualmente e num futuro próximo se tornarão completamente obsoletas.

\section{iii) Horizonte de planejamento do MPS}

Para Xie et al. (2003), em ambientes com demanda incerta e restrições de capacidade, aumentos no horizonte de planejamento levam à diminuição dos custos e aumento nos níveis de serviço, porém aumentam a instabilidade do sistema. Portanto, é necessário que haja uma análise do trade off entre custos e nível de serviço e instabilidade no sistema na determinação do horizonte de planejamento.

\section{iv) Erros de previsão}

Erros na previsão aumentam a instabilidade no sistema (HO \& IRELAND, 1993). Sobre a relação entre os erros na previsão e os custos totais dentro do contexto do MRP, Enns (2002), Wemmerlov (1986) e Zhao \& Lee (1993) defendem que os erros na previsão aumentam o custo total e reduzem o nível de serviço.

\section{v) Estoque de segurança}

Os estoques de segurança são utilizados para fazer frente às incertezas quanto ao processo e quanto à demanda do item. Para Ho \& Ho (1999) a utilização de estoques de segurança e de tempos de segurança minimiza o impacto da instabilidade do sistema no sistema de produção. Porém, estoques levam a aumentos de custos, portanto a adoção de uma abordagem probabilística é recomendável para a diminuição destes custos, ao mesmo tempo em que se diminui a instabilidade do sistema.

\section{vi) Regras de tamanho de lote}

Para Ho \& Ho (1999) a escolha do tamanho do lote visa contribuir para reduzir a instabilidade em sistemas MRP. Muitos modelos de tamanho de lote foram desenvolvidos para trabalhar dentro do ambiente MRP e são comparados em diversos trabalhos (PUJAWAN \& KINGSMAN, 2003; HO, 2002; HO \& HO, 1999; MOLINDER \& OLHAGER, 1998). São eles: i) o clássico lote econômico de compra (EOQ); ii) a quantidade lote por lote (L4L): a quantidade pedida é exatamente igual à necessidade; iii) o método das necessidades fixas do período (FPR): neste método, o tamanho de lote é igual à demanda de um período predeterminado, como por exemplo uma semana ou um mês; iv) a quantidade do 
pedido periódico (POQ): é o EOQ arredondado para uma quantidade inteira de períodos; v) o método do menor custo total (LTC): o tamanho de lote é aquele que minimiza o custo total geral; vi) o algoritmo de SilverMeal (SM): é método no qual o tamanho de lote minimiza o custo no período; vii) o método do menor custo unitário (LUC): neste método o lote minimiza o custo unitário; viii) o método do balanceamento de partes no período (PPB): o lote neste caso minimiza a diferença entre os custos do pedido e os custos de estoque.

Molinder \& Olhager (1998) concluem que a estratégia de produzir a quantidade exata (lote por lote) é a melhor escolha quando se deseja minimizar o leadtime acumulado e a variabilidade no leadtime. Dentre os métodos que levam em consideração os custos, o algoritmo de SilverMeal é o que apresenta o melhor desempenho. Quanto à capacidade de trazer estabilidade ao sistema, a regra de dimensionamento lote por lote (L4L) é tida por pesquisadores e práticos como sendo a melhor prática para itens finais. Este fato é comprovado por Ho \& Ho (1999), porém com duas restrições: baixo custo de set-up e ambientes nos quais a demanda por um item não ocorre em certos períodos, ou seja existe uma grande proporção de períodos com demanda igual a zero (este fato é denominado na literatura de lumpy demand). Estes mesmos autores concluem que o modelo do lote econômico não traz melhorias na instabilidade do sistema MRP. Esta afirmação é confirmada por Ho (2002). Além do método lote por lote para itens finais sob as condições citadas, outros estudos comprovam que pelo menos outras três regras de dimensionamento de tamanho de lote são eficazes para reduzir a instabilidade no MRP. São elas: o algoritmo SM (citado nos trabalhos de HO \& HO,1999; PUJAWAN \& KINGSMAN, 2003), o método PPB (citado nos trabalhos de HO, 2002 e HO \& HO, 1999) e o método LTC (citado no trabalho de HO, 2002).

vii) Leadtimes: Para Corrêa et al. (2001), todos os componentes do leadtime devem estar incluídos quando o leadtime é calculado, e estes tempos devem ser medidos e estar coerentes com a realidade. Ainda de acordo com este autor, dois tipos de erros são bastante comuns na definição do leadtime: o subdimensionamento do leadtime, no qual tempos importantes não são considerados, e o superdimensionamento, no qual são considerados tempos maiores do que os reais para que exista uma "folga" no pla- nejamento. Ambos os procedimentos devem ser combatidos, uma vez que levam a aumentos na instabilidade do sistema. Um outro problema que afeta uma grande parte dos sistemas MRP existentes é a consideração de leadtimes fixos. Porém, já existem sistemas MRP que não apresentam este tipo de restrição; um algoritmo que serve para calcular o leadtime em função da carga real e da capacidade é o algoritmo de Karni (1982). Uma última observação a respeito da determinação dos leadtimes: estes parâmetros devem ser continuamente avaliados para refletir as alterações reais que estão acontecendo na produção.

\section{A parametrização correta envolve a definição do MPS, da freqüência de replanejamento, do horizonte de planejamento, da previsão de demanda, dos estoques de segurança, das regras de tamanho de lote, do leadtime e da política de gestão de estoques.}

viii) Sistema de controle de estoques: a escolha entre a utilização da própria lógica MRP e lógicas de controle de estoques de itens de demanda independente (sistema de revisão contínua - caso particular: duas gavetas - e sistema de revisão periódica) afetam os níveis de estoque e o grau de estabilidade do sistema MRP. Essas lógicas são geralmente vistas como algo excludente na literatura de Gestão da Produção (HAUTANIEMI \& PIRTTILÄ, 1999); em outras palavras, a literatura não trata a fundo o uso combinado dessas lógicas. Baseados nesta premissa, estes autores propuseram um sistema de classificação baseado em três parâmetros (valor do item determinado por uma classificação $\mathrm{ABC}$; leadtime de fornecimento e distribuição da demanda), que auxilia na identificação de quando um desses dois sistemas deve ser utilizado dentro de um ambiente MRP. Resumidamente, o sistema de revisão contínua ou o sistema de revisão periódica devem ser utilizados dentro de um ambiente MRP para controlar os estoques dos itens C (itens de menor valor), ou então os estoques dos itens A (maior valor) no caso em que o leadtime de fornecimento é muito longo, a demanda é baixa e de difícil previsão (esta afirmação é suportada por JACOBS \& WHYBARK, 1992, para os quais se a previsão apresenta erros e a demanda é flutuante, o 
sistema de revisão contínua consegue resultados melhores que o MRP com menor esforço).

Analisando o que foi exposto nesta seção, é proposto o quadro 1 o qual sugere alguns procedimentos a respeito da parametrização do MRP para a redução da instabilidade.

\section{Planejamento e programação integrados}

Com relação à integração do planejamento e programação da produção propomos um algoritmo que trabalha com períodos de "congelamento" (time fence). Para facilitar o seu entendimento e evitar repetição, este algoritmo será mostrado mais adiante, devidamente exemplificado dentro do contexto da empresa pesquisada.

\section{O ESTUDO DE CASO: IMPLANTAC̣ÃO DO MÉTODO PROPOSTO}

O método proposto neste trabalho foi introduzido no departamento de produtos para supermercados da empresa. Como vimos, ele se baseia em dois elementoschave: a correta parametrização do sistema visando uma redução na instabilidade e a adoção de um planejamento e programação da produção integrados, visando o estabelecimento de um MPS factível levando-se em conta as restrições de capacidade. Nesta seção mostramos como estes elementos foram introduzidos na empresa.

Com relação à adoção de um período de congelamento, foi introduzido na empresa o método baseado em períodos, pois como salientamos anteriormente, apesar de o método baseado em ordens apresentar melhores resultados, na prática, este método gera grande confusão no sistema, com diferentes horizontes de congelamento para os diversos itens finais. Quanto ao tipo dos períodos de "congelamento" decidiu-se pela utilização de time fences múltiplos, que como vimos se comportam melhor do que o time fence simples. Já o período de "congelamento" deve ser determinado com relação ao leadtime dos itens. Em média, o leadtime do item final é de aproximadamente uma semana, dos itens de nível 1 também aproximadamente de uma semana e dos itens de nível 2, de duas semanas. Portanto, temos um leadtime acumulado de quatro semanas. Somando-se estas quatro semanas a uma semana, que é o intervalo de replanejamento, temos um período de congelamento de no mínimo cinco semanas para os itens finais, quatro semanas para os itens nível 1 e três semanas para os itens nível 2 (estes valores seriam ideais para o time fence simples). Porém, como adotamos o time fence múltiplo, temos que os períodos de "congelamento" mínimos para os itens dos níveis 0,1 e 2 são de duas, duas e três semanas respectivamente. Já os períodos de "semicongelamento" destes itens são três, duas e uma semana respectivamente. Para facilitar os cadastros e visando uma melhoria mais rápida na instabilidade do sistema, adotamos períodos iguais para todos os itens independentemente de seu nível. Portanto, adotamos um período de congelamento igual a

Quadro 1: Procedimentos a respeito da parametrização no MRP para se reduzir instabilidade no sistema.

\begin{tabular}{|c|c|}
\hline PARÂMETRO & PROCEDIMENTOS \\
\hline $\begin{array}{l}\text { Período de } \\
\text { congelamento }\end{array}$ & $\begin{array}{l}\text { Desde que possível, aumentar o período de congelamento; utilizar período de congelamento } \\
\text { múltiplo. }\end{array}$ \\
\hline $\begin{array}{l}\text { Freqüência de } \\
\text { replanejamento }\end{array}$ & $\begin{array}{l}\text { Deve ser maior ou igual ao período de congelamento se isso não provocar uma grande } \\
\text { mudança na cultura da empresa; as mensagens de reprogramação não devem ser } \\
\text { colocadas em prática se estiverem dentro do período de congelamento. }\end{array}$ \\
\hline $\begin{array}{l}\text { Horizonte de } \\
\text { planejamento }\end{array}$ & O horizonte de planejamento deve ser o menor possível. \\
\hline Erros na previsão & Devem ser evitados erros na previsão. \\
\hline $\begin{array}{l}\text { Estoques de } \\
\text { segurança }\end{array}$ & $\begin{array}{l}\text { Para itens com instabilidade de demanda acentuada, utilizar estoques de segurança já que } \\
\text { eles minimizam o impacto da instabilidade. }\end{array}$ \\
\hline $\begin{array}{l}\text { Regras de } \\
\text { tamanho de } \\
\text { lote }\end{array}$ & $\begin{array}{l}\text { Dê preferência às regras de tamanho de lote que levam à redução da instabilidade no } \\
\text { sistema, a saber: L4L (para itens finais no caso de baixo set-up e lumpy demand), SM, } \\
\text { LTC, PPB. }\end{array}$ \\
\hline Leadtime & $\begin{array}{l}\text { Dimensionar de forma precisa o leadtime, já que sub ou superdimensionamento levam ao } \\
\text { aumento da instabilidade no sistema. }\end{array}$ \\
\hline $\begin{array}{l}\text { Sistema de controle } \\
\text { de estoques }\end{array}$ & $\begin{array}{l}\text { O sistema de revisão contínua ou o de revisão periódica são mais adequados para controlar } \\
\text { itens com demanda independente; contudo, se o item for item } C \text { (item de menor valor), ou } \\
\text { então item A (maior valor) com leadtime de fornecimento muito longo, demanda baixa e de } \\
\text { difícil previsão, ele também é convenientemente controlado por um desses dois sistemas. }\end{array}$ \\
\hline
\end{tabular}


três semanas (15 dias úteis), com mais uma semana "semicongelada" para todos os itens relativos ao setor estudado. A empresa pretende no futuro talvez diminuir este período de congelamento para duas semanas e aumentar para duas semanas o de semicongelamento, visando aumentar a flexibilidade. Sugerimos que esta variação de time fences seja feita de acordo com períodos do ano nos quais a flexibilidade é mais necessária, como por exemplo, na época de lançamento de novos produtos, que na empresa acontece no início do segundo semestre.

Foi determinada uma freqüência de replanejamento de uma semana. Uma freqüência maior (pelo menos igual ao período de congelamento), como recomenda a literatura, significaria uma mudança de cultura muito grande na empresa. No futuro talvez isto possa ser possível, mas no momento é inviável. Foi determinado que este replanejamento ocorrerá no final da semana com uma "rodada" de MRP. Quanto às mensagens de reprogramação, determinou-se que estas só serão levadas em consideração para o próximo período fora do time fence, ou seja, não são feitas reprogramações dentro do time fence e nem "rodadas" do MRP antes do final de semana. O horizonte de planejamento foi reduzido para dois meses (oito semanas), também objetivando a redução da instabilidade no sistema.

Para corrigir os erros nas previsões foram introduzidas análises de erros de previsões como os métodos do menor desvio médio absoluto e o sinal de acompanhamento (ver DAVIS et al., 2001; SIPPER \& BULFIN, 1997). Juntamente com estas análises passaram a ser utilizados métodos mais eficazes para a previsão, como métodos que levam em consideração efeitos de tendência e sazonalidade.

Foram introduzidas regras dinâmicas e probabilísticas para a determinação dos estoques de segurança, principalmente para as matérias-primas. O sistema MRP dispõe desta ferramenta e faz este cálculo automaticamente. As regras de tamanho de lote foram alteradas visando à redução do leadtime, dos estoques e da instabilidade no sistema. Portanto foi definida a regra lote por lote (L4L) para os produtos finais e a regra do menor custo total (LTC) para os itens semi-acabados (o sistema calcula automaticamente este tipo de lote). No futuro espera-se configurar o sistema para o cálculo de outras regras como o algoritmo de Silver-Meal (SM) e o método do balanceamento de partes periódicas (PPB).

Quanto aos leadtimes, está sendo feito um grande esforço para ajustar seu valores no MRP de acordo com a realidade da produção. Com relação aos sistemas de controle de estoques foi proposto o controle dos estoques da empresa utilizando o método proposto por Hautaniemi \& Pirttilä (1999), o qual utiliza o sistema de revisão contínua dentro do ambiente MRP para controlar os estoques dos itens $\mathrm{C}$ (itens de menor valor), e dos itens A (maior valor) no caso em que o leadtime de fornecimento é muito longo e a demanda é baixa e de difícil previsibilidade. Os outros itens são controlados via MRP.

\section{ra a integração do planejamento e programação da produção propomos goritmo que iterativamente e}

O outro elemento-chave para se conseguir a estabilidade no sistema está relacionado à estrutura do planejamento e programação da produção (ver Figura 2). Propusemos um algoritmo para se conseguir uma integração entre o planejamento e a programação visando um MPS factível (disponibilidade de material e restrições de capacidade no curto prazo atendidas). Este algoritmo é mostrado na Figura 3. O algoritmo inicia-se (passo 1) no último dia da semana com a geração de uma lista de ordens de produção, de acordo com a regra EDD (ou seja, são programadas primeiro as ordens mais próximas às datas de entrega) dentro do time fence (três semanas). Para cada ordem, seguindo a prioridade da lista, são verificadas a disponibilidade de materiais e a capacidade (passo 2). Caso existam materiais e capacidade disponíveis para a ordem em questão, a área de produtos para supermercados "fixa" (determina data de início e conclusão para a ordem por meio da programação para a frente) as ordens de produção dentro do time fence e também dentro da semana de semicongelamento (passo 3). Caso contrário, a ordem em questão não é alocada para a produção dentro deste ciclo de planejamento. Quando todas as ordens da lista tiverem sido consideradas, as áreas que fornecem produtos para a área de supermercados também obtêm a programação congelada (passo 4) para seus itens, baseada na programação dos itens acabados realizada. A área de planejamento central altera (passo 5) o plano agregado de famílias de produtos para ficar compatível com a programação já obtida. No final da semana considerada ocorre a "rodada" do MRP (passo 6), do tipo regenerativa, ou seja, todas as ordens, exceto as que estiverem fixadas dentro do time fence e da semana de semicongelamento, são replanejadas. As ordens dentro da semana de semicongelamento podem ser alteradas, já as dentro do período de congelamento não podem sofrer alterações. No início da 
semana, os resultados são programações viáveis dentro do time fence, sendo que as necessidades futuras não fixadas são colocadas automaticamente fora do time fence. Este procedimento é "rolante", ou seja, acontece a cada final de semana. Na verdade, conforme este procedimento se repete, no final da semana o programador só programa da a terceira semana para a frente, uma vez que as duas próximas já estão programadas.

Não se encontrou na literatura sobre gestão da produção um algoritmo tão completo sobre integração de planejamento e programação no curto prazo levando em conta a capacidade. Um algoritmo que também pretende integrar os processos de planejamento e programação da produção dentro de um ambiente MRP é encontrado em Taal \& Wortmann (1997), porém nosso algoritmo é bem mais abrangente, uma vez que engloba aspectos do time fence, importantíssimos para a redução da instabilidade no sistema, e mostra as relações e a integração entre as diferentes áreas da empresa relacionadas ao planejamento e controle.

\section{O ESTUDO DE CASO: RESULTADOS}

Foram avaliados indicadores de desempenho algumas semanas antes e depois da implantação do método na empresa. Os resultados são mostrados a seguir.

i) valor do estoque: foram avaliados os valores e quantidades dos estoques quatro semanas antes e depois da introdução das melhorias. Constatou-se que houve uma redução média de $39 \%$ no valor e de $42 \%$ nas quantidades em estoque dos produtos acabados do setor pesquisado. Quanto aos produtos acabados dos outros setores e semi-acabados a redução foi menor uma vez que esta é medida em função de todos os outros produtos que a empresa trabalha e nestes setores o método ainda não foi implementado. Mesmo assim, houve uma redução de $9 \%$ nos valores em estoque e de $11 \%$ nas quantidades.

ii) nível de serviço ao cliente: Foram avaliadas o número de pedidos seis semanas antes e seis semanas depois da introdução das melhorias propostas. Constatouse uma redução de $35 \%$ no número de pedidos em atraso relativo aos produtos do departamento de supermercados.

iii) grau de instabilidade do sistema: vários indicadores de instabilidade no MRP são propostos na literatura, dentre eles o método SBU (Sridharan et al., 1988), o método BKM (BLACKBURN et al., 1986), o método KS (KADIPASAOGLU \& SRIDHARAN, 1997) e a medida de reprogramação ponderada de Ho \& Ho (1999). Neste trabalho foi utilizado o método KS, que em relação aos outros métodos apresenta a vantagem de levar em consideração todos os níveis da estrutura dos produtos. A fórmula para o cálculo da instabilidade, de acordo com este método, é mostrada a seguir (fórmula 1). onde:

I = instabilidade do sistema MRP

$\mathrm{j}=$ nível do item, $\mathrm{j}=0, \ldots \ldots, \mathrm{m}$;

$\mathrm{i}=$ item i no nível $\mathrm{j}, \mathrm{i}=1, \ldots \ldots, \mathrm{n}_{\mathrm{j}}$

$\mathrm{t}=$ período de tempo;

$\mathrm{N}=$ tamanho do horizonte de planejamento;

$\mathrm{k}=$ ciclo de planejamento;

$\mathrm{M}_{\mathrm{k}_{k}}=$ período inicial do ciclo de planejamento $\mathrm{k}$;

$Q_{i j t}^{k}=$ a quantidade da ordem (aberta e ou planejada) para o item i no nível $\mathrm{j}$ no período $\mathrm{t}$ durante o ciclo de planejamento k;

$\alpha=$ parâmetro de ponderação para os períodos, com $0<\alpha<1$;

$\beta=$ parâmetro de ponderação para os níveis da estrutura do produto, com $0<\beta<1$.

Pequenos valores nos parâmetros $\alpha$ e $\beta$ significam rápido declínio das ponderações para os períodos e para os níveis da estrutura dos produtos respectivamente. Para o nosso cálculo da instabilidade no sistema utilizamos valores de $\alpha$ e $\beta$ igual a 0,2 , pois desejamos fornecer maior peso a tempos mais recentes e níveis mais baixos das estruturas dos produtos. Utilizamos no cálculo somente os três primeiros níveis das estruturas, excluindo as matérias-primas, pois a grande maioria destas, como vimos, é controlada por políticas de ponto de reposição, e, portanto, não sofre tanto com instabilidades no sistema.

Os cálculos da instabilidade antes e depois da introdução das melhorias propostas são mostrados nas Tabelas 1, 2 e 3 e nas Tabelas 4, 5 e 6, respectivamente. Os cálculos iniciam no ciclo de planejamento $\mathrm{k}=2$, uma vez que somente neste ciclo podem-se calcular as diferenças entre as quantidades planejadas no ciclo $2\left(Q_{i j t}^{k}\right)$ e no ciclo anterior $1\left(Q_{i j t}^{k-1}\right)$. Isto também é feito nos ciclos 3 (diferença entre ciclo 3 e 2) e 4 (diferença entre ciclo 4 e 3 ). Podemos notar que a instabilidade antes da introdução da melhoria tinha um valor de 27.154,6 (soma dos totais das Tabelas 1, 2 e 3). Após quatro semanas da introdução das mudanças esta instabilidade caiu para 3.824,6 (soma dos totais das Tabelas 4, 5 e 6). A redução na instabilidade no sistema foi de $85,9 \%$.

iv) Grau de satisfação e confiança das pessoas no sistema: este indicador foi medido qualitativamente por meio de entrevistas com os apontadores e programadores 
Figura 3: Método para um planejamento e programação da produção integrados, com a utilização do time fence.

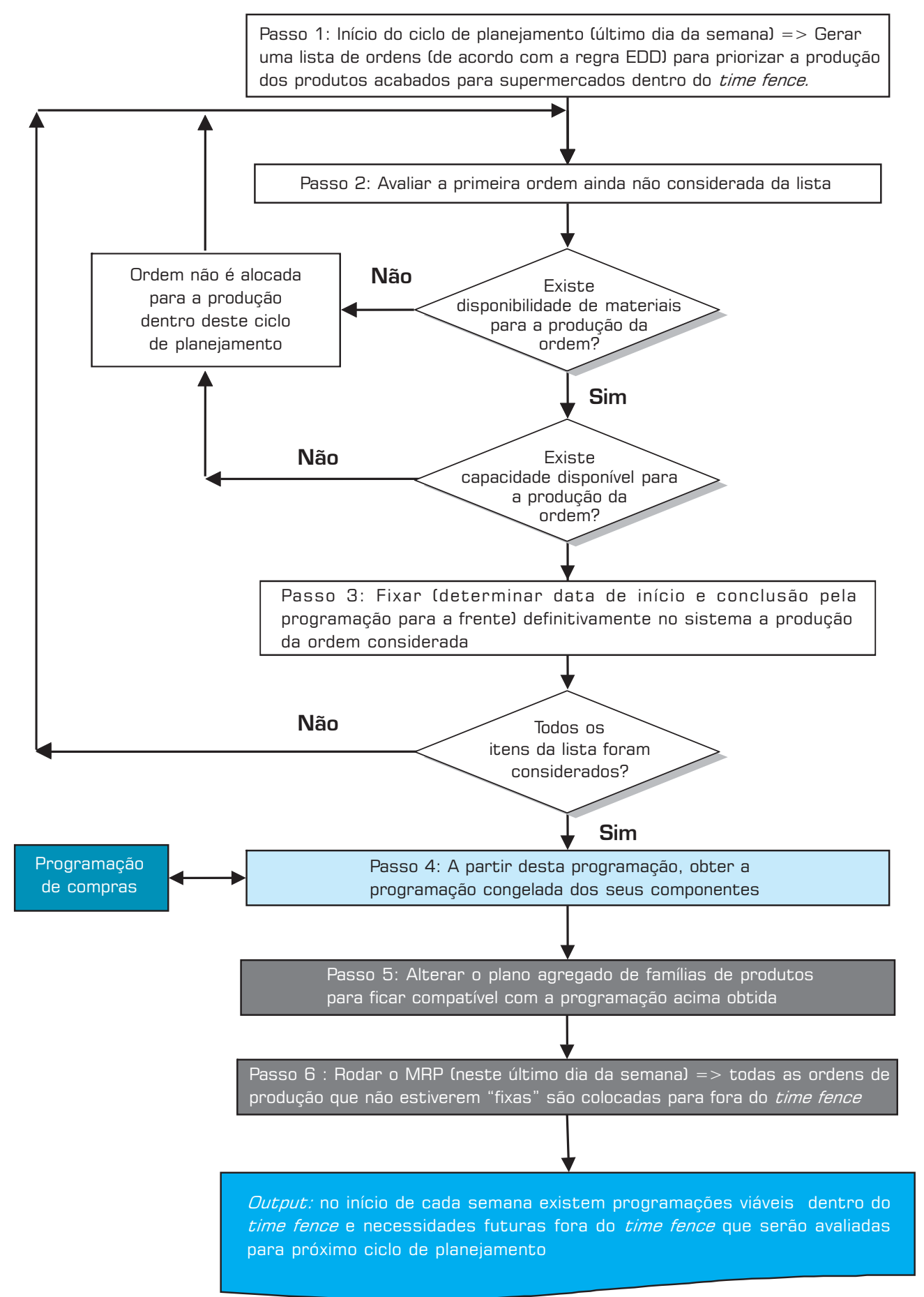

$=>$ atividade da área de planejamento

$=>$ atividade da área de programação de produtos acabados para supermercados

$=>$ atividade da área de programação de produtos acabados que são componentes dos produtos para supermercados

$=>$ atividade da área de programação de compras (matérias-primas) 
Tabela 1: Cálculos da instabilidade no MRP antes da implantação do método proposto: ciclo de planejamento 2. Ciclo de planejamento 2

\begin{tabular}{|c|c|c|c|c|c|c|c|c|c|c|}
\hline & \multicolumn{2}{|c|}{ Itens nível 0} & \multicolumn{2}{|c|}{ Itens nível 1} & \multicolumn{2}{|c|}{ Itens nivel 2} & \multirow{2}{*}{\multicolumn{4}{|c|}{ Cálculos finais }} \\
\hline $\begin{array}{l}\text { Ponderação } \\
\text { nível }(\beta]\end{array}$ & \multicolumn{2}{|c|}{$(1-0,2)^{\star} 0,2^{0}$} & \multicolumn{2}{|c|}{$(1-0,2)^{\star} 0,2^{1}$} & \multicolumn{2}{|c|}{$(1-0,2) * 0,2^{2}$} & & & & \\
\hline $\begin{array}{l}\text { Ponderação } \\
\text { período }[\alpha]\end{array}$ & Período & $\begin{array}{l}\text { Somatório } \\
\text { Diferença } \\
\text { quantidades }\end{array}$ & Período & $\begin{array}{l}\text { Somatório } \\
\text { Diferença } \\
\text { quantidades }\end{array}$ & Período & $\begin{array}{l}\text { Somatório } \\
\text { Diferença } \\
\text { quantidades }\end{array}$ & $\begin{array}{l}\text { Somatório } \\
\text { ponderado } \\
\text { nível } 0\end{array}$ & $\begin{array}{l}\text { Somatório } \\
\text { ponderado } \\
\text { nivel } 1\end{array}$ & $\begin{array}{l}\text { Somatório } \\
\text { ponderado } \\
\text { nivel } 2\end{array}$ & $\begin{array}{l}\text { Somatório } \\
\text { total }\end{array}$ \\
\hline$(1-0,2)^{*} 0,2^{0}$ & 2 & 5000 & 2 & 20000 & 2 & 22000 & 3200,0 & 2560,0 & 563,2 & 6323,2 \\
\hline$(1-0,2)^{*} 0,2^{1}$ & 3 & 12000 & 3 & 12000 & 3 & 20000 & 1536,0 & 307,2 & 102,4 & 1945,6 \\
\hline$(1-0,2) * 0,2^{2}$ & 4 & 23000 & 4 & 21000 & 4 & 22000 & 588,8 & 107,5 & 22,5 & 718,8 \\
\hline$(1-0,2)^{*} 0,2^{3}$ & 5 & 40000 & 5 & 35000 & 5 & 32000 & 204,8 & 35,8 & 6,6 & 247,2 \\
\hline$(1-0,2)^{*} 0,2^{4}$ & 6 & 51000 & 6 & 47000 & 6 & 32000 & 52,2 & 9,6 & 1,3 & 63,2 \\
\hline$(1-0,2) * 0,2^{5}$ & 7 & 60000 & 7 & 55000 & 7 & 49000 & 12,3 & 2,3 & 0,4 & 14,9 \\
\hline$(1-0,2)^{*} 0,2^{6}$ & 8 & 57000 & 8 & 54000 & 8 & 48000 & 2,3 & 0,4 & 0,1 & 2,9 \\
\hline & & & & & & Totais & 5596,4 & 3022,9 & 696,5 & 9315,8 \\
\hline
\end{tabular}

Tabela 2: Cálculos da instabilidade no MRP antes da implantação do método proposto: ciclo de planejamento 3.

\section{Ciclo de planejamento 3}

\begin{tabular}{|c|c|c|c|c|c|c|c|c|c|c|}
\hline \multirow{3}{*}{$\begin{array}{l}\text { Ponderação } \\
\text { nível }(\beta) \\
\begin{array}{l}\text { Ponderação } \\
\text { período }\end{array}\end{array}$} & \multirow{2}{*}{\multicolumn{2}{|c|}{$\begin{array}{l}\text { Itens nivel } 0 \\
(1-0,2)^{\star} 0,2^{\circ}\end{array}$}} & \multirow{2}{*}{\multicolumn{2}{|c|}{$\begin{array}{l}\text { Itens nivel } 1 \\
(1-0,2)^{\star} 0,2^{1}\end{array}$}} & \multicolumn{2}{|c|}{ Itens nivel 2} & \multirow{2}{*}{\multicolumn{4}{|c|}{ Cálculos finais }} \\
\hline & & & & & \multicolumn{2}{|c|}{$(1-0,2) * 0,2^{2}$} & & & & \\
\hline & Período & $\begin{array}{l}\text { Somatório } \\
\text { Diferença } \\
\text { quantidades }\end{array}$ & Período & $\begin{array}{l}\text { Somatório } \\
\text { Diferença } \\
\text { quantidades }\end{array}$ & Período & $\begin{array}{l}\text { Somatório } \\
\text { Diferença } \\
\text { quantidades }\end{array}$ & $\begin{array}{l}\text { Somatório } \\
\text { ponderado } \\
\text { nível } 0\end{array}$ & $\begin{array}{l}\text { Somatório } \\
\text { ponderado } \\
\text { nivel } 1\end{array}$ & $\begin{array}{l}\text { Somatório } \\
\text { ponderado } \\
\text { nivel } 2\end{array}$ & $\begin{array}{l}\text { Somatório } \\
\text { total }\end{array}$ \\
\hline$(1-0,2) * 0,2^{0}$ & 3 & 8000 & 3 & 11000 & 3 & 9000 & 5120,0 & 1408,0 & 230,4 & 6758,4 \\
\hline$(1-0,2)^{*} 0,2^{1}$ & 4 & 9000 & 4 & 14000 & 4 & 20000 & 1152,0 & 358,4 & 102,4 & 1612,8 \\
\hline$(1-0,2)^{*} 0,2^{2}$ & 5 & 16000 & 5 & 21000 & 5 & 24000 & 409,6 & 107,5 & 24,6 & 541,7 \\
\hline$(1-0,2)^{*} 0,2^{3}$ & 6 & 24000 & 6 & 22000 & 6 & 24000 & 122,9 & 22,5 & 4,9 & 150,3 \\
\hline$(1-0,2)^{*} 0,2^{4}$ & 7 & 45000 & 7 & 43000 & 7 & 54000 & 46,1 & 8,8 & 2,2 & 57,1 \\
\hline$(1-0,2)^{*} 0,2^{5}$ & 8 & 64000 & 8 & 54000 & 8 & 64000 & 13,1 & 2,2 & 0,5 & 15,8 \\
\hline$(1-0,2)^{*} 0,2^{6}$ & 9 & 56000 & 9 & 56000 & 9 & 65000 & 2,3 & 0,5 & 0,1 & 2,9 \\
\hline & & & & & & Totais & 6866,0 & 1907,9 & 365,1 & 9139,0 \\
\hline
\end{tabular}

Tabela 3: Cálculos da instabilidade no MRP antes da implantação do método proposto: ciclo de planejamento 4. Ciclo de planejamento 4

\begin{tabular}{|c|c|c|c|c|c|c|c|c|c|c|}
\hline \multirow{2}{*}{$\begin{array}{l}\text { Ponderação } \\
\text { nivel }(\beta)\end{array}$} & \multicolumn{2}{|c|}{ Itens nível 0} & \multicolumn{2}{|c|}{ Itens nivel 1} & \multicolumn{2}{|c|}{ Itens nivel 2} & \multirow{2}{*}{\multicolumn{4}{|c|}{ Cálculos finais }} \\
\hline & \multicolumn{2}{|c|}{$(1-0,2)^{\star} 0,2^{0}$} & \multicolumn{2}{|c|}{$(1-0,2)^{\star} 0,2^{1}$} & \multicolumn{2}{|c|}{$(1-0,2)^{*} 0,2^{2}$} & & & & \\
\hline $\begin{array}{l}\text { Ponderação } \\
\text { período }\end{array}$ & Período & $\begin{array}{l}\text { Somatório } \\
\text { Diferença } \\
\text { quantidades }\end{array}$ & Período & $\begin{array}{l}\text { Somatório } \\
\text { Diferença } \\
\text { quantidades }\end{array}$ & Período & $\begin{array}{l}\text { Somatório } \\
\text { Diferença } \\
\text { quantidades }\end{array}$ & $\begin{array}{l}\text { Somatório } \\
\text { ponderado } \\
\text { nível } 0\end{array}$ & $\begin{array}{l}\text { Somatório } \\
\text { ponderado } \\
\text { nivel } 1\end{array}$ & $\begin{array}{l}\text { Somatório } \\
\text { ponderado } \\
\text { nivel } 2\end{array}$ & $\begin{array}{l}\text { Somatório } \\
\text { total }\end{array}$ \\
\hline$(1-0,2)^{*} 0,2^{0}$ & 4 & 7000 & 4 & 8000 & 4 & 10000 & 4480,0 & 1024,0 & 256,0 & 5760,0 \\
\hline$(1-0,2)^{*} 0,2^{1}$ & 5 & 12000 & 5 & 17000 & 5 & 14000 & 1536,0 & 435,2 & 71,7 & 2042,9 \\
\hline$(1-0,2)^{*} 0,2^{2}$ & 6 & 18000 & 6 & 24000 & 6 & 21000 & 460,8 & 122,9 & 21,5 & 605,2 \\
\hline$(1-0,2)^{*} 0,2^{3}$ & 7 & 31000 & 7 & 36000 & 7 & 32000 & 158,7 & 36,9 & 6,6 & 202,1 \\
\hline$(1-0,2)^{*} 0,2^{4}$ & 8 & 54000 & 8 & 64000 & 8 & 48000 & 55,3 & 13,1 & 2,0 & 70,4 \\
\hline$(1-0,2)^{*} 0,2^{5}$ & 9 & 63000 & 9 & 62000 & 9 & 63000 & 12,9 & 2,5 & 0,5 & 16,0 \\
\hline$(1-0,2)^{*} 0,2^{6}$ & 10 & 67000 & 10 & 52000 & 10 & 60000 & 2,7 & 0,4 & 0,1 & 3,3 \\
\hline & & & & & & Totais & 6706,5 & 1635,0 & 358,3 & 8699,8 \\
\hline
\end{tabular}


Tabela 4: Cálculos da instabilidade no MRP depois da implantação do método proposto: ciclo de planejamento 2. Ciclo de planejamento 2

\begin{tabular}{|c|c|c|c|c|c|c|c|c|c|c|}
\hline & Itens ní & 0 & Itens nív & & Itens nív & & & & & \\
\hline $\begin{array}{l}\text { Ponderação } \\
\text { nível }(\beta]\end{array}$ & $(1-0,2)$ * & & $(1-0,2) *$ & & $(1-0,2) * C$ & & & Cálculo & finais & \\
\hline $\begin{array}{l}\text { Ponderação } \\
\text { período }\end{array}$ & Período & $\begin{array}{l}\text { Somatório } \\
\text { Diferença } \\
\text { quantidades }\end{array}$ & Período & $\begin{array}{l}\text { Somatório } \\
\text { Diferença } \\
\text { quantidades }\end{array}$ & Período & $\begin{array}{l}\text { Somatório } \\
\text { Diferença } \\
\text { quantidades }\end{array}$ & $\begin{array}{l}\text { Somatório } \\
\text { ponderado } \\
\text { nivel } 0\end{array}$ & $\begin{array}{l}\text { Somatório } \\
\text { ponderado } \\
\text { nível } 1\end{array}$ & $\begin{array}{l}\text { Somatório } \\
\text { ponderado } \\
\text { nivel } 2\end{array}$ & $\begin{array}{l}\text { Somatório } \\
\text { total }\end{array}$ \\
\hline$(1-0,2) * 0,2^{0}$ & 2 & 0 & 2 & 0 & 2 & 0 & 0,0 & 0,0 & 0,0 & 0,0 \\
\hline$(1-0,2) * 0,2^{1}$ & 3 & 0 & 3 & 0 & 3 & 0 & 0,0 & 0,0 & 0,0 & 0,0 \\
\hline$(1-0,2) * 0,2^{2}$ & 4 & 31000 & 4 & 28000 & 4 & 23000 & 793,6 & 143,4 & 143,4 & 960,5 \\
\hline$(1-0,2) * 0,2^{3}$ & 5 & 34000 & 5 & 35000 & 5 & 26000 & 174,1 & 35,8 & 35,8 & 215,2 \\
\hline$(1-0,2) * 0,2^{4}$ & 6 & 32000 & 6 & 33000 & 6 & 31000 & 32,8 & 6,8 & 6,8 & 40,8 \\
\hline$(1-0,2) * 0,2^{5}$ & 7 & 30000 & 7 & 32000 & 7 & 40000 & 6,1 & 1,3 & 1,3 & 7,8 \\
\hline$(1-0,2)^{*} 0,2^{6}$ & 8 & 41000 & 8 & 44000 & 8 & 54000 & 1,7 & 0,4 & 0,4 & 2,1 \\
\hline & & & & & & Totais & 1008,3 & 187,6 & 187,6 & 1226,5 \\
\hline
\end{tabular}

Tabela 5: Cálculos da instabilidade no MRP depois da implantação do método proposto: ciclo de planejamento 3. Ciclo de planejamento 3

\begin{tabular}{|c|c|c|c|c|c|c|c|c|c|c|}
\hline \multirow{3}{*}{$\begin{array}{l}\text { Ponderação } \\
\text { nivel }[\beta] \\
\begin{array}{l}\text { Ponderação } \\
\text { período }\end{array}\end{array}$} & \multicolumn{2}{|c|}{ Itens nível 0} & \multicolumn{2}{|c|}{ Itens nivel 1} & \multicolumn{2}{|c|}{ Itens nivel 2} & \multirow{2}{*}{\multicolumn{4}{|c|}{ Cálculos finais }} \\
\hline & \multicolumn{2}{|c|}{$(1-0,2) * 0,2^{0}$} & \multicolumn{2}{|c|}{$(1-0,2) * 0,2^{1}$} & \multicolumn{2}{|c|}{$(1-0,2) * 0,2^{2}$} & & & & \\
\hline & Período & $\begin{array}{l}\text { Somatório } \\
\text { Diferença } \\
\text { quantidades }\end{array}$ & Período & $\begin{array}{l}\text { Somatório } \\
\text { Diferença } \\
\text { quantidades }\end{array}$ & Período & $\begin{array}{l}\text { Somatório } \\
\text { Diferença } \\
\text { quantidades }\end{array}$ & $\begin{array}{l}\text { Somatório } \\
\text { ponderado } \\
\text { nível } 0\end{array}$ & $\begin{array}{l}\text { Somatório } \\
\text { ponderado } \\
\text { nível } 1\end{array}$ & $\begin{array}{l}\text { Somatório } \\
\text { ponderado } \\
\text { nível ? }\end{array}$ & $\begin{array}{l}\text { Somatório } \\
\text { total }\end{array}$ \\
\hline$(1-0,2) \div 0,2^{0}$ & 3 & 0 & 3 & 0 & 3 & 0 & 0,0 & 0,0 & 0,0 & 0,0 \\
\hline$(1-0,2)^{*} 0,2^{1}$ & 4 & 0 & 4 & 0 & 4 & 0 & 0,0 & 0,0 & 0,0 & 0,0 \\
\hline$(1-0,2) * 0,2^{2}$ & 5 & 35000 & 5 & 39000 & 5 & 26000 & 896,0 & 199,7 & 26,6 & 1122,3 \\
\hline$(1-0,2) * 0,2^{3}$ & 6 & 31000 & 6 & 27000 & 6 & 34000 & 158,7 & 27,6 & 7,0 & 193,3 \\
\hline$(1-0,2)^{*} 0,2^{4}$ & 7 & 24000 & 7 & 33000 & 7 & 32000 & 24,6 & 6,8 & 1,3 & 32,6 \\
\hline$(1-0,2) * 0,2^{5}$ & 8 & 35000 & 8 & 31000 & 8 & 32000 & 7,2 & 1,3 & 0,3 & 8,7 \\
\hline$(1-0,2)^{*} 0,2^{6}$ & 9 & 42000 & 9 & 47000 & 9 & 48000 & 1,7 & 0,4 & 0,1 & 2,2 \\
\hline & & & & & & Totais & 1088,2 & 235,7 & 35,2 & 1359,2 \\
\hline
\end{tabular}

Tabela 6: Cálculos da instabilidade no MRP depois da implantação do método proposto: ciclo de planejamento 4. Ciclo de planejamento 4

\begin{tabular}{|c|c|c|c|c|c|c|c|c|c|c|}
\hline \multirow{3}{*}{$\begin{array}{l}\text { Ponderação } \\
\text { nível }(\beta) \\
\begin{array}{l}\text { Ponderação } \\
\text { período }\end{array}\end{array}$} & \multirow{2}{*}{\multicolumn{2}{|c|}{$\begin{array}{l}\text { Itens nivel } 0 \\
(1-0,2)^{\star 0} 0,2^{\circ}\end{array}$}} & \multirow{2}{*}{\multicolumn{2}{|c|}{$\begin{array}{l}\text { Itens nivel } 1 \\
(1-0,2)^{\star} 0,2^{1}\end{array}$}} & \multicolumn{2}{|c|}{ Itens nível 2} & \multirow{2}{*}{\multicolumn{4}{|c|}{ Cálculos finais }} \\
\hline & & & & & \multicolumn{2}{|c|}{$(1-0,2)^{\star} 0,2^{2}$} & & & & \\
\hline & Período & $\begin{array}{l}\text { Somatório } \\
\text { Diferença } \\
\text { quantidades }\end{array}$ & Período & $\begin{array}{l}\text { Somatório } \\
\text { Diferença } \\
\text { quantidades }\end{array}$ & Período & $\begin{array}{l}\text { Somatório } \\
\text { Diferença } \\
\text { quantidades }\end{array}$ & $\begin{array}{l}\text { Somatório } \\
\text { ponderado } \\
\text { nivel } 0\end{array}$ & $\begin{array}{l}\text { Somatório } \\
\text { ponderado } \\
\text { nivel } 1\end{array}$ & $\begin{array}{l}\text { Somatório } \\
\text { ponderado } \\
\text { nivel } 2\end{array}$ & $\begin{array}{l}\text { Somatório } \\
\text { total }\end{array}$ \\
\hline$(1-0,2)^{*} 0,2^{0}$ & 4 & 0 & 4 & 0 & 4 & 0 & 0,0 & 0,0 & 0,0 & 0,0 \\
\hline$(1-0,2) * 0,2^{1}$ & 5 & 0 & 5 & 0 & 5 & 0 & 0,0 & 0,0 & 0,0 & 0,0 \\
\hline$(1-0,2) * 0,2^{2}$ & 6 & 30000 & 6 & 27000 & 6 & 35000 & 768,0 & 138,2 & 35,8 & 942,1 \\
\hline$(1-0,2)^{*} 0,2^{3}$ & 7 & 40000 & 7 & 33000 & 7 & 31000 & 204,8 & 33,8 & 6,3 & 244,9 \\
\hline$(1-0,2)^{*} 0,2^{4}$ & 8 & 31000 & 8 & 37000 & 8 & 36000 & 31,7 & 7,6 & 1,5 & 40,8 \\
\hline$(1-0,2) * 0,2^{5}$ & 9 & 36000 & 9 & 42000 & 9 & 39000 & 7,4 & 1,7 & 0,3 & 9,4 \\
\hline$(1-0,2)^{*} 0,2^{6}$ & 10 & 34000 & 10 & 38000 & 10 & 44000 & 1,4 & 0,3 & 0,1 & 1,8 \\
\hline & & & & & & Totais & 1013,3 & 181,6 & 44,1 & 1239,0 \\
\hline
\end{tabular}


da produção antes e depois das mudanças. É um indicador importante, pois se as pessoas não confiam no sistema tendem a não utilizar suas potencialidades. Antes da implementação do método, o sistema era bastante malvisto pelos apontadores da produção, programadores e mesmo por chefes de departamento da produção na empresa, devido à grande instabilidade que apresentava. Oito semanas após a introdução das melhorias foi realizada uma entrevista com estes profissionais da área envolvida nas mudanças. Esta entrevista constatou um grande aumento no grau de confiança e satisfação das pessoas no sistema. Isto é um prérequisito para o sucesso e total utilização do sistema.

integrados e voltados para a criação de um MPS factível de acordo com as restrições de capacidade. Um algoritmo para se conseguir esta estrutura é proposto neste trabalho. Com esses dois procedimentos consegue-se superar dois dos principais problemas que afetam os sistemas MRP: erros na parametrização do sistema e a abordagem infinita de capacidade. Com isto consegue-se reduzir a instabilidade do sistema MRP, levando a melhorias significativas no seu desempenho, como redução dos estoques e aumento do nível de serviço aos clientes.

O método proposto foi implementado em um setor da empresa (no momento, a empresa estuda a adoção das melhorias para os seus outros departamentos) e conseguiram-se resultados muito positivos: redução de $85,9 \%$ na instabilidade no sistema, com conseqüente redução de $39 \%$ nos custos de estoques e de $42 \%$ nos níveis de estoque dos produtos acabados do departamento; redução de $9 \%$ nos custos e $11 \%$ nos níveis de estoque de

Um outro indicador que não foi medido, pois só mostrará efeitos no longo prazo, são os custos associados a quantidades refugadas por produtos que saem de linha, vencendo a validade. Estes custos eram em grande parte ocasionados pela instabilidade no sistema. Com a melhoria desta, acredita-se que, no longo prazo, este indicador apresentará grandes melhorias.

\section{CONCLUSÕES}

Este trabalho apresenta a proposta de um método para a redução da instabilidade e melhoria no desempenho do sistema MRP em um estudo de caso, uma grande empresa produtora de materiais para escrita. $\mathrm{O}$ método defende que dois procedimentos são essenciais para se conseguir tais objetivos: i) melhorar a parametrização do MRP de modo a minimizar a instabilidade do sistema; ii) adotar uma estrutura de programação e controle da produção outros departamentos; redução de $35 \%$ nos atrasos nas ordens de clientes e aumento no grau de confiança e satisfação dos trabalhadores no MRP. Academicamente, este trabalho é pioneiro no tratamento do problema da parametrização e da instabilidade do MRP num estudo de caso em empresa brasileira. Além disso, propõe um algoritmo para se trabalhar com períodos de planejamento "congelados" (time fence), tornando o sistema "finito no curto prazo" e reduzindo a instabilidade do sistema.

Vale ressaltar que o método pode facilmente ser adaptado e aplicado em empresas industriais de outros segmentos que utilizem o MRP. As adaptações necessárias dizem respeito à parametrização do MRP, que, embora devam seguir algumas diretrizes, apontadas neste artigo, para se conseguir a estabilidade do sistema, também depende de características dos produtos e dos processos de fabricação e compras da empresa. Esta versatilidade de implantação do método é uma das principais contribuições deste trabalho.

\section{Artigo recebido em 24/03/2005 \\ Aprovado para publicação em 19/09/2005}

\section{- Referências Bibliográficas}

BLACKBURN, J.D.; KROPP, D.H.; MILLEN, R.A. A comparison of strategies to dampen nervousness in MRP systems. Management Science, v. 33, n. 4, p. 413-429, 1986.

BRYMAN, A. Research methods and organization studies. London: Routledge (Taylor \& Francis Group), 1989.
CARLSON, R.C.; JUCKER, J.V.; KROPP, D.H. Less nervous MRP systems: a dynamic economic lot-sizing approach. Management Science, v. 25, n. 8, p. 754-761, 1979.

CORRÊA, H. L. \& GIANESI, I. G. N. Just in Time, MRP II e OPT - Um enfoque estratégico. Ed. Atlas, 2. ed. 1996.
CORRÊA, H. L.; GIANESI, I. G. N.; CAON, M. Planejamento, Programação e Controle da produção. $4^{\mathrm{a}} \mathrm{Ed}$. Editora Atlas, São Paulo, 2001.

DAVIS, M. M.; AQUILANO, N. J. CHASE, R. B. Fundamentos da Administração da Produção. 3. ed. Porto Alegre: Bookman Editora, 2001.
ENNS, S. T. MRP performance effects due to forecast bias and demand uncertainty. European Journal of Operational Research, v. 138 , p. 87 102, 2002.

EUWE, M. J.; JANSEN, P. A.; VELDKAMP, C. T. H. The value of rescheduling functionality within standard MRP packages. Production Planning \& Control, v. 9, n. 9, p. 328-334, 1998. 


\section{- Referências Bibliográficas}

GODOY, A. S. A pesquisa qualitativa e sua utilização em administração de empresas. Revista de Administração de Empresas, v. 35, n. 4, EADSP-FGV, São Paulo, 1995.

HAUTANIEMI, P. \& PIRTTILÄ, T. The choice of replenishment policies in an MRP environment. International Journal of Production Economics, v. 59, p. 85-92, 1999.

HO, C. Evaluating dampening effects of alternative lot-sizing rules to reduce MRP systems nervousness. International Journal of Production Research, v. 40, n. 11, p. 2633-2652, 2002.

HO, C. Evaluating the impact of operating environment on MRP system nervousness. International Journal of Production Research, v. 27, n. 7, p. 1115-1135, 1989.

HO, C. \& HO, S.J.K. Evaluating the effectiveness of using lot- sizing rules to cope with MRP system nervousness. Production Planning and Control, v. 10, n. 2, p. $150-161,1999$.

HO, C.; LAW, W.K.; RAMPAL, R. Uncertainty-dampening methods for reducing MRP systems nervousness. International Journal of Production Research, v. 33, n. 2, p. 483-496, 1995.

HO, C. \& IRELAND, T.C. Correlating MRP system nervousness with forecast errors. International Journal of Production Research, v. 36, n. 8, p. 2285-2299, 1998.
JACOBS, F. R. \& WHYBARK, D. C. A comparison of reorder point and material requirements planning inventory control logic. Decision Sciences, v. 23, n. 2, p. 332-342, 1992

KADIPASAOGLU, S. N. \& SRIDHARAN, S. V. Measurement of instability in multi-level MRP systems. International Journal of Production Research, v. 35, n. 3, p.713-737, 1997.

KARNI, R. Capacity Requirements Planning - a systematization. International Journal of Production Research, v. 20, n. 6, p. 715-739, 1982.

KOH, S. C. L.; SAAD, S. M.; JONES, M. $H$. Uncertainty under MRP-planned manufacture: review and categorization. International Journal of Production Research, v. 40, n. 10, p. 2399-2421, 2002.

MACCARTHY, B. L. \& FERNANDES, F C. A multidimensional Classification of Production Systems for the Design and Selection of Production Planning and Control Systems. Production Planning \& Control, v. 11, n. 5, 2000.

MATHER, H. Reschedule the reschedules you just rescheduled way of life for MRP. Production and Inventory Management Journal, 18, p. 60-79, 1977.

MOLINDER, A. \& OLHARGER, J. The effect of MRP lot sizing on actual cumulative leadtimes in multi-level systems. Production Planning \& Control, v. 9 , n. 3, p. 293-302, 1998.
PUJAWAN, I. N. \& KINGSMAN, B. G. Properties of lot-sizing rules under lumpy demand. International Journal of Production Economics, n. 81-82, p. 215307, 2003.

SIPPER, D. \& BULFIN JR.; R. L. Production Planning, Control and Integration. New York: Mc Graw Hill, 1998

SRIDHARAN, V. \& BERRY, W. L. Freezing the Master Porduction Schedule Under Demand Uncertainty. Decision Sciences, v. 21, p. 97-120, 1990.

SRIDHARAN, V.; BERRY, W. L.; UDAYABHANU, V. Freezing the Master Production Schedule Under Rolling Planning Horizons. Management Science, v. 33, n. 9, September 1987.

SRIDHARAN, V.; BERRY, W. L.; UDAYABANU, V. Measuring master production schedule stability under rolling planning horizons. Decision Sciences, v. 19, n. 1, p. 147-166, 1988.

STEELE, D. C. The nervous MRP systems: how to do battle. Production and Inventory Management Journal, 4 th quarter, p. 83-89, 1975.

STEVENS, A. L. The material manager's role in master production schedule in a material requirements planning environment. Proceedings of the American Production and Inventory Control Society Conference, p. 121-133, 1977.

TAAL, M. \& WORTMANN, J. C. Integrating MRP and finite capacity planning. Production Planning \& Control, v. 8, n. 3, p. 245-254, 1997.
TEMPELMEIER, H. Resource-constrained materials requirements planning MRP rc. Production Planning 8 Control, v. 8, n. 5, p. 451-461, 1997.

WEMMERLOV, U A time-phase orderpoint system in environments with and without demand uncertainty. International Journal of Production Research, v. 24, n. 2, p. 343-358, 1986.

XIE, J.; ZHAO, X.; LEE, T. S. Freezing the master production schedule under single resource constraint and demand uncertainty. Internationa Journal of Production Economics, 83, p. 65-84, 2003

YEUNG, J. H. Y: MA, L. LAWS, J. S. The impact of using multiple freeze fences on costs in MRP systems. International Journal of Production Research, v. 41, n. 10 , p. 2201-2228, 2003.

YEUNG, J. H. Y.; WONG, W. C. K.; $M A$, L. Parameters affecting the effectiveness of MRP systems: a review. International Journal of Production Research, v. 36, n. 2, p. 313 331, 1998.

YEUNG, J. H. Y; WONG, W. C. K.; MA L.; LAW, J. S. MSP with multiple freeze fences in multi-product multilevel MRP systems. International Journal of Production Research, v. 37 n. 13, p. 2977-2996, 1999.

YIN, R. K. Case study research - design and methods. Sage Publications, $2^{\text {nd }}$ edition, 1994.

ZHAO, X. \& LEE, T. S. Freezing the MPS for MRP systems under demand uncertainty. Journal of Operations Management, v. 11, p. 185-205, 1993.

\section{- Sobre os autores}

\section{Moacir Godinho Filho}

Doutor em Engenharia de Produção pela Universidade Federal de São Carlos

Mestre em Engenharia de Produção pela Universidade Federal de São Carlos

Professor Adjunto nível I - Universidade Federal de São Carlos

Departamento de Engenharia de Produção - Programa de Pós-Graduação

Endereço: Rod. Washington Luís, Km 235 - CEP 13565-905 - São Carlos - SP

Telefone: (16) 3351-8237 ramal 235

E-mail:moacir@dep.ufscar.br

\section{Flavio Cesar Faria Fernandes}

Pós-Doutor em PCP pela The University of Notthinghan

Doutor em Engenharia pela Escola de Engenharia de São Carlos da Universidade de São Paulo

Mestre em Engenharia de Produção pela Escola Politécnica da Universidade de São Paulo

Professor Adjunto nível IV - Universidade Federal de São Carlos

Departamento de Engenharia de Produção - Programa de Pós-Graduação

Endereço: Rod. Washington Luís, Km 235 - CEP 13565-905 - São Carlos - SP

Telefone: (16) 3351-8237 ramal 214

E-mail: dfcf@power.ufscar.br 